\title{
Self-Assembly of Conjugated Metallopolymers with Tunable Length and Controlled Regiochemistry
}

\author{
Jake L. Greenfield, Felix J. Rizzuto, leva Goldberga and Jonathan R. Nitschke ${ }^{\star[a]}$
}

\begin{abstract}
Self-assembled materials can be designed to express useful optoelectronic properties; however, control over structure is a necessary precondition for the optimization of desired properties. Here we report a simple, metal-templated polymerization process that generates helical metallopolymer strands over 75 repeat units long $(28 \mathrm{kDa})$ from a single bifunctional monomer and $\mathrm{Cu}^{\prime}$. The resulting polymer consists of a double helix of two identical conjugated organic strands enclosing a central column of metal ions. The length of this metallopolymer can be controlled by adding monofunctional subcomponents to end-cap the conjugated ligands. The use of ditopic and bulky monotopic subcomponents, respectively, allows for a head-to-head or head-to-tail double helix to be generated. Spectroscopic measurements of different polymer lengths demonstrate how control over polymer length leads to control over the electronic and luminescent properties of the resulting material, allowing for tunable white-light emission.
\end{abstract}

Self-assembling polymers are attractive functional materials for the next generation of devices: their facile bottom-up synthesis and inherent error-checking mechanisms enable useful functions to manifest under well-defined conditions. ${ }^{[1]}$ Polymeric chains that are not prepared through self-assembly may nonetheless assemble into higher ordered structures; for example, during the self-organization of polymers into micelles. ${ }^{[2]}$ The dynamic behavior of such assemblies typically derives from intermolecular interactions between polymer chains, as opposed to reorganization within chains. ${ }^{[1,3]}$ Metallopolymers, in which monomer units come together through coordination to metal centers, ${ }^{[4]}$ are capable of reorganizing both between and within polymer chains, thanks to the reversibility of coordinative interactions. ${ }^{[5]}$ These materials have exhibited high luminescence efficiencies, ${ }^{[6]}$ stimuli-responsive behavior, ${ }^{[7]}$ selfhealing properties ${ }^{[8]}$ and have been used to construct molecular electronics devices. ${ }^{[1 e, 9]}$

Recently, others ${ }^{[7 a, 10]}$ and our group ${ }^{[11]}$ have demonstrated that metallopolymers can be generated by subcomponent self-assembly, wherein amine and aldehyde subcomponents condense around metal ions, forming dynamic covalent ${ }^{[12]} \mathrm{C}=\mathrm{N}$ and coordinative $\mathrm{N} \rightarrow$ Metal bonds simultaneously. ${ }^{[13]}$ Polymer growth is favored by the strong mutual reinforcement between these two linkages, allowing for the self-assembly of functional and persistent structures. ${ }^{[7 a]}$ The resulting metallopolymers can exhibit reversible stimuli-responsive behavior and have been incorporated into various devices; $[7 \mathrm{a}, 11 \mathrm{~b}, 11 \mathrm{c}, 14]$ however, control over the length and polymerization process of these materials is

[a] J. L., Greenfield, F. J. Rizzuto, I. Goldberga, Prof. J. R. Nitschke Chemistry Department

University of Cambridge

Lensfield Road

Cambridge, CB2 1EW (United Kingdom)

E-mail: jrn34@cam.ac.uk

Supporting information for this article is given via a link at the end of the document. yet to be demonstrated. Controlling the structure and conjugation length of the organic portion of metallopolymers is crucial to optimizing their electronic properties. Polymer length also determines the morphology of the material, impacting device performance, scalability of preparation, and solution processability, ${ }^{[15]}$ which are essential considerations for bespoke device fabrication. ${ }^{[16]}$

We hypothesized that a metallopolymer consisting of conjugated organic ligands that are tightly wrapped around an array of metal ions would yield useful length-dependent optoelectronic properties. ${ }^{[9 a, 17]}$ Similar helical polymeric motifs ${ }^{[18]}$ are of biological relevance, ${ }^{[19]}$ and are of interest in the field of foldamers, ${ }^{[19,20]}$ polarized light emission ${ }^{[21]}$ and spintronics. ${ }^{[22]}$ In the present work we have developed self-complementary monomer units $\mathbf{A}$ and $\mathbf{B}$ that polymerize around $\mathrm{Cu}^{\mathrm{l}}$ template ${ }^{[23]}$ ions to yield double-helical metallopolymers 1 and 2 , respectively (Scheme 1). Whereas the aldehyde and amine functionalities in subcomponent self-assembly have heretofore been present on different building blocks, ${ }^{[7 a, 11 a, 11 b]}$ here we have integrated them into the same monomer unit. Such bifunctional monomers are capable of generating much longer polymer chains than a mixture of separate diamine and dialdehyde subcomponents, where the need for stoichiometric balance limits the maximum extent of polymer growth. ${ }^{[24]}$ In addition, employing this asymmetric monomer unit gives rise to regioisomers, imparting directionality to the polymer growth.

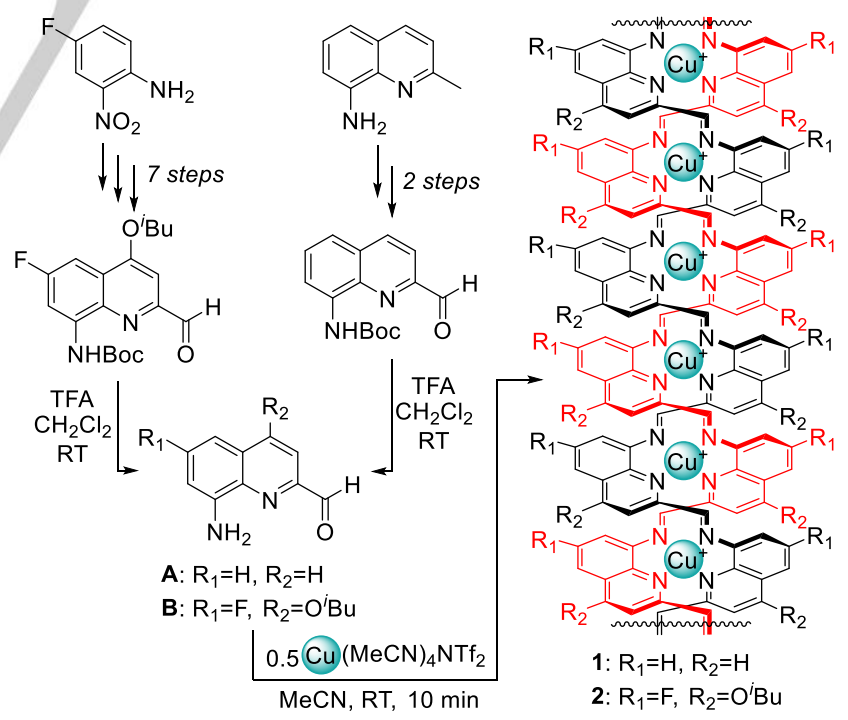

Scheme 1. Imine condensation of monomers $\mathbf{A}$ and $\mathbf{B}$ around $\mathrm{Cu}^{\prime}$ centers affords double-helical metallopolymers $\mathbf{1}$ and $\mathbf{2}$, respectively. Counterions have been omitted and one strand has been drawn in red for clarity. Experimental details are provided in Section 3 of the Supporting Information.

Our system thus allows for long polymers (averaging 75 repeat units, $28 \mathrm{kDa}$ ) to be generated. Oligomers could also be produced with moderate polydispersities and predictable chain lengths when the monofunctional terminating groups $\mathbf{C}$ and $\mathbf{D}$ shown in Figure 1 were employed, as noted using dynamic light 
scattering (DLS, Figure 1b). Solutions of polymers 1 and 2 exhibited emissive behavior that was dependent upon the length of the metallopolymer. Increasing polymer length resulted in a bathochromic shift of the emission maximum by $50 \mathrm{~nm}$ (Figure 4a).
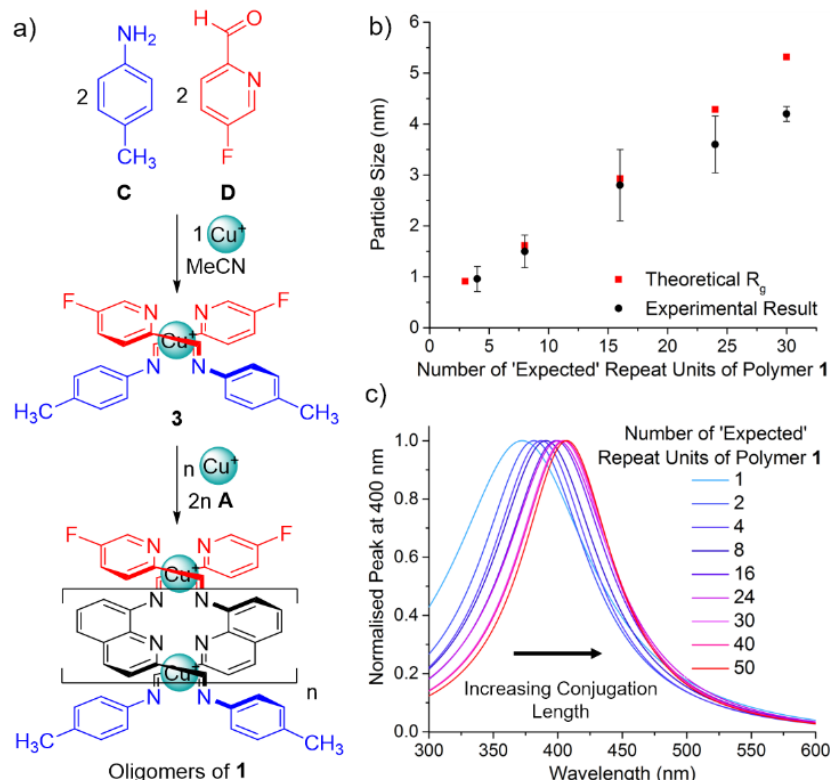
c)

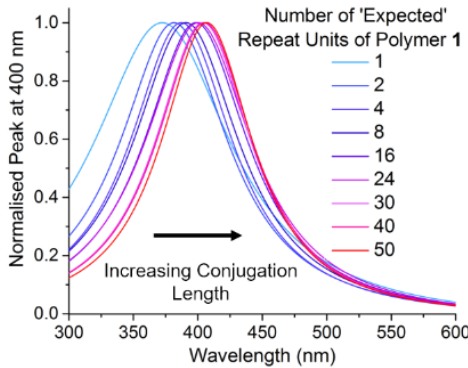

Figure 1. a) By varying the stoichiometry of the terminating groups $\mathbf{C}$ and $\mathbf{D}$ the length of polymer $\mathbf{1}$ (and 2) can be controlled. b) The plot of the average particle size obtained from number\% DLS measurements. The theoretical length was calculated using the radius of gyration $(\mathrm{Rg})$ of a cylinder. The measured polydispersity of the metallopolymers is shown as error bars (Table S1). The moderate to broad dispersities are attributed to varying degrees of aggregation between samples. c) The fitted $\pi \rightarrow \pi^{*}$ absorption band red-shifts for polymers of increasing length.

Bifunctional monomer unit $\mathbf{A}$ was synthesized in good yield based on the route described by Zaccheroni and coworkers. ${ }^{[25]}$ Fluorinated congener $\mathbf{B}$ was prepared using a modification of the procedure of Huc and coworkers, appending an O'Bu group to the monomer for improved solubility. ${ }^{[26]}$ Monomer A was predominantly used in this work due to its highly scalable synthesis, while monomer $\mathbf{B}$ was employed primarily in ${ }^{19} \mathrm{~F}$ NMR investigations, easing the identification of regioisomers and oligomers of different lengths.

Polymers 1 and $\mathbf{2}$ (Scheme 1) were prepared by combining either $\mathbf{A}$ or $\mathbf{B}$ (2 equiv), respectively, and $\mathrm{Cu}^{\prime}$ trifluoromethanesulfonimide (triflimide, $\mathrm{NTf}_{2}, 1$ equiv) in dry and degassed $\mathrm{CH}_{3} \mathrm{CN}$ or DMSO. Molecular modeling of a short strand (8 repeat units) of polymer 1 using an MM3 force field suggested that two strands were required to satisfy the preferred tetrahedral coordination geometry of $\mathrm{Cu}^{\prime}$ (Figure S3). This leads the conjugated polymer strands to twist and coil, yielding a helical geometry (Figure S4). A broadening of the ${ }^{1} \mathrm{H}$ NMR spectrum occurred during polymerization (Figure S5), which coincided with the observation of larger particles in solution by DLS. Two populations of differently sized species were observed in the ranges of $1-10$ and $30-500 \mathrm{~nm}$ (Figure S6), which we attribute to individual metallopolymer strands and aggregates, respectively. Neither population was observed in control DLS measurements of only monomer $\mathbf{A}$ or $\mathrm{CuNTf}_{2}$ solutions.
Despite the exposed hydrophobic surface of the organic sheath, polymer 1 could be rendered water soluble by anion exchange of $\mathrm{NTf}_{2}{ }^{-}$for $\mathrm{SO}_{4}{ }^{2-}$ (Supporting Information Section 5.3). UV-Vis measurements indicated that the sulfate salt of 1 exhibited no signs of degradation over 5 days. DLS showed no change in the lengths of the polymer, which we attribute to the stability of imines coordinated to $\mathrm{Cu}^{\prime}$ in water ${ }^{[1 \mathrm{1f}]}$ (Figure S9). To complement DLS measurements (Figure S6, S7 and S9), the weight distribution of the sulfate salt of $\mathbf{1}$ was investigated in water using analytical ultracentrifugation (AUC), wherein sedimentation was monitored using both UV-Vis spectroscopy and interference refractometry. ${ }^{[27]}$ The mean weight of the polymer corresponded to a 75-mer using both detection methods (Figure S11 and S12). We attribute termination of polymer growth to occur at a solubility threshold. Monomer purity is also inferred to limit growth.

The length of metallopolymers $\mathbf{1}$ and 2 could be manipulated by the addition of an amine, $\mathbf{C}$, and an aldehyde, $\mathbf{D}$, to cap the aldehyde- and amine-termini of the conjugated chains, respectively. Varying the stoichiometry between these capping groups and the monomer subcomponent afforded polymers of different lengths (Figure 1a). In the absence of monomer $\mathbf{A}$ or $\mathbf{B}$, mononuclear complex $\mathbf{3}$ formed from the condensation of $\mathbf{C}$ and D around a $\mathrm{Cu}^{\prime}$ template. This complex was observed to rearrange upon the addition of $\mathbf{A}$ or $\mathbf{B}$ and additional $\mathrm{Cu}^{\prime}$ to give terminated oligomeric species (Figure S13). Signals corresponding to residues of $\mathbf{B}$ and $\mathbf{D}$ within discrete oligomers were identifiable in the ${ }^{19} \mathrm{~F}$ NMR spectrum (Figure S14). Comparison of the number and integrated intensities of signals of $\mathbf{B}$ residues in the ${ }^{19} \mathrm{~F}$ NMR spectrum with respect to those in the $\mathbf{D}$ region enabled the assignment of oligomers of varying length, ranging from mononuclear species to a 3-mer.

The electronic properties of a metallopolymer vary as a function of length; increasing conjugation length results in decreased HOMO/LUMO gaps. ${ }^{[28]}$ Thus, bathochromic shifts in the UV-vis spectra were used to gauge the relative lengths of metallopolymers (Figure 1c). Polymers formed using monomer:end-group ratios ranging from $1: 1$ to $50: 1$ were prepared and their spectral features compared. The $\pi \rightarrow \pi^{*}$ bands of the conjugated strands were observed protruding from the tail of a broad absorption band, the breadth of which was attributed to Rayleigh scattering of larger particles in the UV-Vis spectra. The UV-Vis absorption profile responded to changes in polymer length, which were more readily seen when the spectra were normalized to absorption intensity at $300 \mathrm{~nm}$ (Figure S15). The band centered at ca. $400 \mathrm{~nm}$ in the UV-Vis spectra was observed to respond most significantly to changes in the ratio between monomer units and end-capping groups. At higher proportions of monomer relative to end-capping groups, a redshift in the $\pi \rightarrow \pi^{*}$ band of the polymer was observed, indicating an increase in conjugation, and thus length (Figure 1c). DLS measurements of these solutions revealed that the expected increase in the number of repeat units coincided with an increase in the average particle size in solution (Figure $1 b$, Figure S7, Table S1).

MM3 molecular models of 1 represent straight, high-aspect ratio polymers; however, the size calculated from the DLS measurement is anticipated to underestimate the true particle size. The size of the polymer particles obtained from DLS 
measurements corresponds to the diameter of a sphere that shares the same translational diffusional parameters as the diffusing polymer. Since prediction of the hydrodynamic radius requires the diffusion coefficient of a polymer to be known, we estimated the radius of gyration, $R_{g}$, of the metallopolymer using the dimensions obtained from the crystallographic data of the 3-mer of polymer 1 (discussed below) to qualitatively evaluate our end-capping method for controlling polymer length. The length of shorter metallopolymers fits well with the expected size (Figure 1c), whereas a deviation is evident for the longer metallopolymers. This deviation is attributed to the differences between calculated $R_{g}$ values and the measured hydrodynamic radii, as well as systematic error in measuring small quantities of terminating groups.

Single crystals of a 3 -mer of polymer $1^{[29]}$ were obtained from the slow diffusion of $\mathrm{Et}_{2} \mathrm{O}$ into a solution of the subcomponents shown in Figure 2 in $\mathrm{CH}_{3} \mathrm{CN}$. The X-ray crystal structure of this 3-mer revealed the expected configuration of two imine-condensed polymer strands twisting around a linear array of copper atoms, affording a double helix (Figure 2). The ends of each ligand strand are terminated by a residue of amine $\mathbf{C}$ and a residue of aldehyde $\mathbf{D}$. Two unique helices are observed in the crystal lattice: one correpsonding to a Head-toHead $(\mathrm{HH})$ regioisomer, and another configuration that may represent the Head-to-Tail (HT) regioisomer (see below, Figure $\mathrm{S} 1$ ). Intriguingly, each $\mathrm{Cu}^{\prime}$ center was disordered over two positions in the $\mathrm{HH}$ regioisomer, leading us to infer that the central $\mathrm{Cu}_{4}{ }_{4}$ column can exist in one of two configurations, each slipped ca. 0.6 $\AA$ with respect to the other. The central $\mathrm{Cu}^{\prime}-\mathrm{Cu}$ separation averaged $3.0 \AA$, a distance expected to allow electronic delocalization between copper centers in partially oxidized species. ${ }^{[1]}$
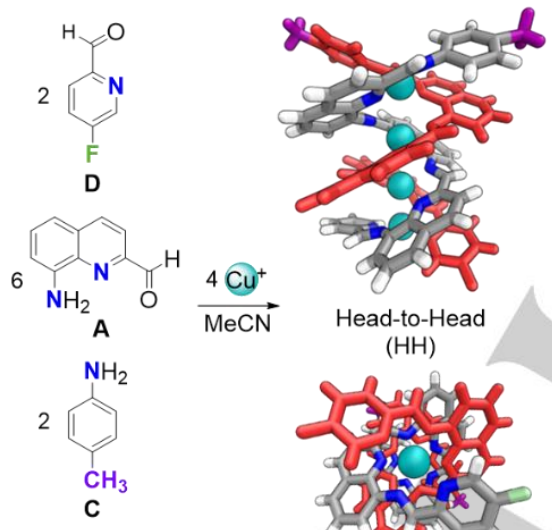
$(\mathrm{HH})$
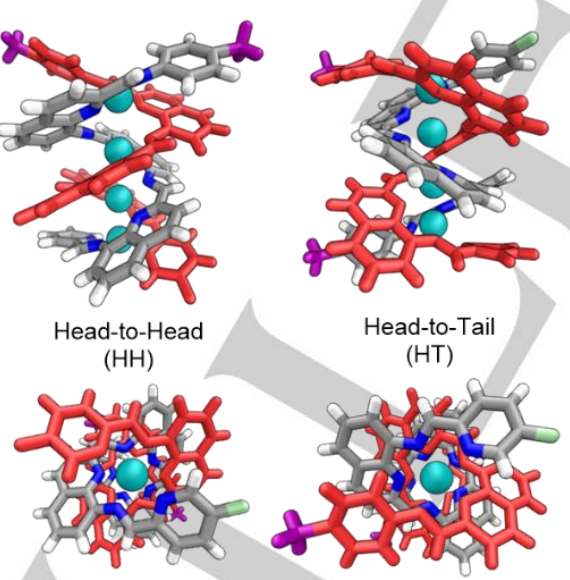

Figure 2. The crystal structure of the 3-mer of polymer $\mathbf{1}$, highlighting the double-helical geometry of the metallopolymers, including views down the helical axis. One strand of each configuration is colored red. The methyl groups of the $p$-toluidine residues are drawn in purple. The disordered helix is represented in a Head-to-Tail configuration. Disorder and counterions are omitted for clarity ( $\mathrm{Cu}$ - cyan, $\mathrm{C}$ - gray, $\mathrm{N}$ - blue, $\mathrm{F}$ - green, $\mathrm{H}$ - white).

The crystal structure of the 3-mer of polymer 1 revealed the possibility of two regioisomers of the metallopolymer. In the $\mathrm{HH}$ isomer, both terminal $\mathbf{C}$ residues of the two helical polymer strands are found on one end of the double helix, and both $\mathbf{D}$ residues on the other. In the HT configuration, each end of the double helix contains one $\mathbf{C}$ and one $\mathbf{D}$ residue (Figure 2). While compositionally identical, the two regioisomers are anticipated to have different polarities, because the dipoles of the two chains oppose in $\mathrm{HT}$, and reinforce each other in $\mathrm{HH}$, resulting in differences in their electronic properties and functions.

For each length of dicopper oligomer, both $\mathrm{HH}$ and HT regioisomers were inferred to form; two sets of signals, each assigned to one of the two isomers, were observed to diffuse at a similar rate in the ${ }^{19} \mathrm{~F}$ DOSY NMR spectrum (Figure S16). Regioisomers of longer oligomers were also identified in ${ }^{19} \mathrm{~F}$ NMR spectra.

By employing different end-capping groups, regiochemistry could be controlled. Two distinct ${ }^{19} \mathrm{~F}$ NMR spectral regions were identified, one of which was inferred to correspond to $\mathrm{HH}$, and the other to HT, environments (Figure S16). When flexible diamine terminating group $\mathbf{F}$ was employed during synthesis, the two strands of the polymer were bridged, yielding a $\mathrm{HH}$ configuration (Figure $3 \mathrm{c}$ ); models indicated that this diamine could not bridge in a HT configuration without severe strain. Evidence for a single $\mathrm{HH}$ configuration was provided by the presence of a single signal in the ${ }^{19} \mathrm{~F}$ NMR spectrum in the region corresponding to residues of $\mathbf{D}$ (Figure S17), as opposed to the two signals that would be expected for the coexisting $\mathrm{HH}$ and HT isomers. An ESI mass spectrum corresponded to the formation of single bridged strands (Figure S18) rather than a dimeric species (Figure $3 \mathrm{~d}$ ).

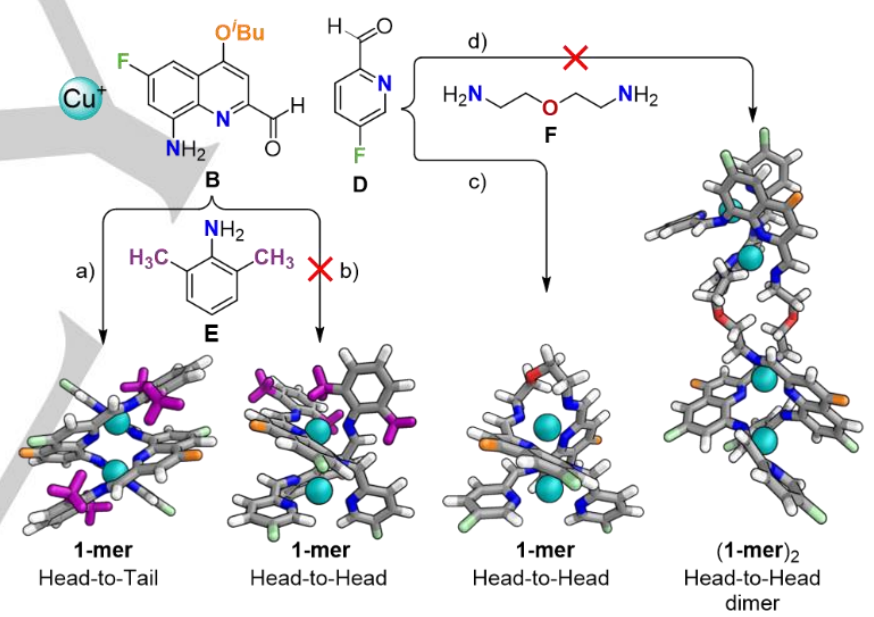

Figure 3. MM3 molecular models of $\mathrm{HT}$ and $\mathrm{HH}$ products, showing the regiochemistry of these assemblies when either a) bulky monoamines or c) flexible diamines were employed during synthesis. The O'Bu substituents have been replaced with orange stubs for clarity. Methyl groups have been colored purple to aid identification.

To optimize instead the formation of the HT isomer, a bulky terminating group, 2,6-dimethylaniline $\mathbf{E}$, was employed (Figure 3a). We hypothesized that the HT arrangement would be preferred in this case to reduce steric clash between the termini of the strands in a $\mathrm{HH}$ arrangement (Figure $3 b$ ). A single set of signals with the same diffusion rate was observed in the ${ }^{19} \mathrm{~F}$ NMR spectrum, with the fluorine signal of $\mathbf{D}$ shifted downfield (Figure S19). We observed that the more upfield-shifted D signals in the ${ }^{19} \mathrm{~F}$ NMR spectra (ca. -116.0 to $-118.0 \mathrm{ppm}$ ) correspond to species with $\mathrm{HH}$ regiochemistry, whereas more downfield-shifted signals ( -114.0 to $-115.5 \mathrm{ppm})$ correspond to the HT isomer (Figure S20).

Metallopolymer $\mathbf{1}$ and its oligomeric congeners exhibited fluorescence behavior in solution, originating from the $\pi \rightarrow \pi^{*}$ excitation. This $S_{1} \rightarrow S_{0}$ emission spans 400 to $700 \mathrm{~nm}$, 
corresponding to white light (Figure S21). Furthermore, the wavelength at maximum emission intensity $\left(\lambda_{\max }\right)$ varied as a function of the metallopolymer length: red-shifts were observed as polymer length increased, attributed to a decrease in the band gap of the polymer (Figure 4a). The color of light emission thus shifts from blue-white for short oligomers to yellow-white for longer polymers (Figure 4b). At maximum length (i.e. with no added terminating groups), the corresponding excitation spectra were broad, with local maxima occurring at ca. $400 \mathrm{~nm}$ and ca. $325 \mathrm{~nm}$. These excitation maxima coincide with the fitted peaks observed in the UV-Vis spectra for metallopolymers of fixed length (Figure S22).
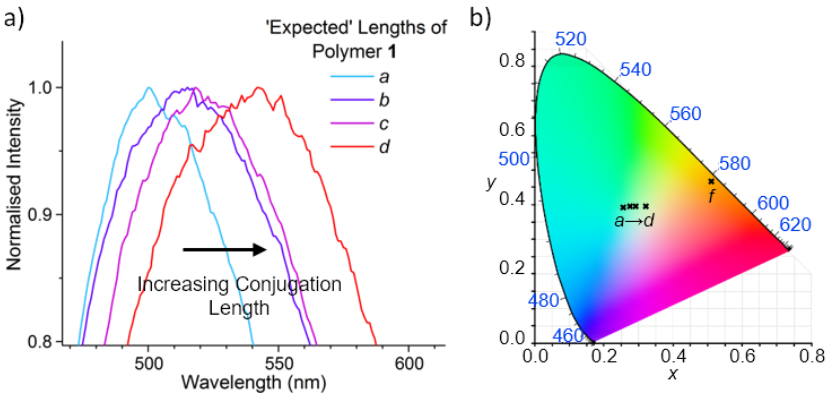

Figure 4. a) The emission spectra (in $\mathrm{MeCN}$ ) of oligomers corresponding to a 13-mer, 30-mer, 50-mer and a non-terminated polymer of 1 (a to $d$, respectively). We do not observe any significant changes in the emission spectrum when the capping-groups are employed, attributed to the greater proportion of the repeat unit with respect to these end-capping groups b) CIE 1931 coordinates show that these species emit white light, shifting $a \rightarrow d$ from blue-white to yellow-white emissions. Monomer A was observed to emit orange light, as indicated by $f$.

We have shown that by combining aldehyde and amine functional groups into the same monomer unit, long, conjugated double-helical metallopolymers can be constructed with minimal synthetic effort. A bottom-up approach to controlling metallopolymer length and regiochemistry was demonstrated to be fruitful, allowing investigations into the effects of these parameters upon structural and electronic properties. We are currently investigating methods to control the helical chirality of these polymers. The orthogonal termini arising from the asymmetry of the monomer units will likewise be exploited for surface functionalization and the study of charge transport through the polymer.

\section{Acknowledgements}

This work was funded by the UK Engineering and Physical Sciences Research Council (EPSRC). FJR acknowledges Cambridge Australia Scholarships and the Cambridge Trust for PhD funding. We thank Diamond Light Source for time on Beamline 119 (MT11397). We also thank Jayamurugan Govindasamy for preliminary studies, Derrick A. Roberts for invaluable discussion and Katherine Stott for assisting with the analytical ultracentrifugation measurements.

Keywords: Self-Assembly • Metallopolymer • Double-Helix • Regioisomers $•$ Fluorescence

[1] a) O. Ikkala, G. ten Brinke, Science 2002, 295, 2407-2409; b) W. G. Skene, J.-M. P. Lehn, Proc. Natl. Acad. Sci. U.S.A 2004, 101, 8270-8275;
C) T. Aida, E. W. Meijer, S. I. Stupp, Science 2012, 335, 813-817; d) N. Roy, B. Bruchmann, J.-M. Lehn, Chem. Soc. Rev. 2015, 44, 3786-3807; e) G. R. Whittell, M. D. Hager, U. S. Schubert, I. Manners, Nat. Mater. 2011, 10, 176-188; f) D. Schultz, F. Biaso, A. R. M. Shahi, M. Geoffroy, K. Rissanen, L. Gagliardi, C. J. Cramer, J. R. Nitschke, Chem. - Eur. J. 2008, 14,7180-7185; g) D. Sánchez-García, B. Kauffmann, T. Kawanami, H. Ihara, M. Takafuji, M.-H. Delville, I. Huc, J. Am. Chem. Soc. 2009, 131, 8642-8648; h) S. Chakrabarti, P. Mukhopadhyay, S. Lin, L. Isaacs, Org. Lett. 2007, 9, 2349-2352; i) R. Sakamoto, T. Yagi, K. Hoshiko, S. Kusaka R. Matsuoka, H. Maeda, Z. Liu, Q. Liu, W. Y. Wong, H. Nishihara, Angew. Chem. Int. Ed. 2017, 10.1002/anie.201611785.

[2] a) K. Matyjaszewski, N. V. Tsarevsky, Nat. Chem. 2009, 1, 276-288; b) A O. Moughton, R. K. O'Reilly, J. Am. Chem. Soc. 2008, 130, 8714-8725.

[3] K. Matyjaszewski, J. Xia, Chem. Rev. 2001, 101, 2921-2990.

[4] M. Kobayashi, D. Savard, A. R. Geisheimer, K. Sakai, D. B. Leznoff, Inorg Chem. 2013, 52, 4842-4852.

[5] R. J. Wojtecki, M. A. Meador, S. J. Rowan, Nat. Mater. 2011, 10, 14-27.

[6] C. A. Strassert, C.-H. Chien, M. D. Galvez Lopez, D. Kourkoulos, D. Hertel, K. Meerholz, L. De Cola, Angew. Chem. Int. Ed. 2011, 50, 946-950.

[7] a) F. Garcia, J. Pelss, H. Zuilhof, M. M. J. Smulders, Chem. Commun. 2016, 52, 9059-9062; b) Y. Wang, H. Xu, X. Zhang, Adv. Mater. 2009, 21 2849-2864; c) J. B. Beck, S. J. Rowan, J. Am. Chem. Soc. 2003, 46, 13922-13923; d) L. Greb, H. Mutlu, C. Barner-Kowollik, J.-M. Lehn, J. Am. Chem. Soc. 2016, 138, 1142-1145.

[8] a) S. Bode, R. K. Bose, S. Matthes, M. Ehrhardt, A. Seifert, F. H. Schacher, R. M. Paulus, S. Stumpf, B. Sandmann, J. Vitz, A. Winter, S. Hoeppener, S. J. Garcia, S. Spange, S. van der Zwaag, M. D. Hager, U. S. Schubert, Polym. Chem. 2013, 4, 4966-4973; b) S. Burattini, D. H. Merino, W. Weng, J. Seppala, H. M. Colquhoun, W. Hayes, M. E. Mackay, I. W. Hamley, S. J. Rowan, J. Am. Chem. Soc. 2010, 132, 12051-12058.

[9] a) G. R. Whittell, I. Manners, Adv. Mater. 2007, 19, 3439-3468; b) M. Frank, J. Ahrens, I. Bejenke, M. Krick, D. Schwarzer, G. H. Clever, J. Am. Chem. Soc. 2016, 138, 8279-8287.

[10] X. Wu, N. Xu, Z. Zhu, Y. Cai, Y. Zhao, D. Wang, Polym. Chem. 2014, 5, 1202-1209.

[11] a) D. Asil, J. A. Foster, A. Patra, X. D. Hatten, J. Barrio, O. A. Scherman, J. R. Nitschke, R. H. Friend, Angew. Chem. Int. Ed. 2014, 53, 8388-8391; b) X. D. Hatten, N. Bell, N. Yufa, G. Christmann, J. R. Nitschke, J. Am. Chem. Soc. 2011, 133, 3158-3164; c) X. D. Hatten, D. Asil, R. H. Friend, J. R. Nitschke, J. Am. Chem. Soc. 2012, 134, 19170-19178; d) R. Kaminker, X. de Hatten, M. Lahav, F. Lupo, A. Gulino, G. Evmenenko, P. Dutta, C. Browne, J. R. Nitschke, M. E. van der Boom, J. Am. Chem. Soc. 2013, 135, 17052-17059; e) M. Hutin, R. Frantz, J. R. Nitschke, Chem. - Eur. J. 2006, 12, 4077-4082.

[12] a) D. Beaudoin, F. Rominger, M. Mastalerz, Angew. Chem. Int. Ed. 2016, DOI: 10.1002/anie.201610782; b) K. Osowska, O. Š. Miljanić, J. Am. Chem. Soc. 2011, 133, 724-727.

[13] a) J. Dömer, J. C. Slootweg, F. Hupka, K. Lammertsma, F. E. Hahn Angew. Chem. Int. Ed. 2010, 49, 6430-6433; b) S. A. Cameron, S. Brooker, A. Three, Inorg. Chem. 2011, 50, 3697-3706.

[14] S. J. Rowan, J. B. Beck, Faraday Discuss. 2005, 128, 43-53.

[15] S. Rosenne, E. Grinvald, E. Shirman, L. Neeman, S. Dutta, O. Bar-Elli, R. Ben-Zvi, E. Oksenberg, P. Milko, V. Kalchenko, H. Weissman, D. Oron, B. Rybtchinski, Nano Lett. 2015, 15, $7232-7237$.

[16] a) N. Sakai, M. Lista, O. Kel, S.-i. Sakurai, D. Emery, J. Mareda, E. Vauthey, S. Matile, J. Am. Chem. Soc. 2011, 133, 15224-15227; b) H. Kang, S. Jung, S. Jeong, G. Kim, K. Lee, Nature. Commun. 2015, 6, 6503; c) C. Shahar, J. Baram, Y. Tidhar, H. Weissman, S. R. Cohen, I. Pinkas, B. Rybtchinski, ACS Nano 2013, 7, 3547-3556.

[17] X. Li, N. Markandeya, G. Jonusauskas, N. D. McClenaghan, V. Maurizot, S. A. Denisov, I. Huc, J. Am. Chem. Soc. 2016, 138, 13568-13578.

[18] a) S. P. Argent, H. Adams, T. Riis-johannessen, J. C. Jeffery, L. P. Harding, W. Clegg, W. Harrington, M. D. Ward, Dalton Trans. 2006, 49965013; b) M. Albrecht, Chem. Rev. 2001, 101, 3457-3497.

[19] a) T. Kawasaki, K. Soai, J. Fluorine Chem. 2010, 131, 525-534; b) E. Yashima, K. Maeda, H. lida, Y. Furusho, K. Nagai, Chem. Rev. 2009, 109, 6102-6211.

[20]a) D. Mazzier, M. Crisma, M. De Poli, G. Marafon, C. Peggion, J. Clayden, A. Moretto, J. Am. Chem. Soc. 2016, 138, 8007-8018; b) C. D. Meyer, C. S. Joiner, J. F. Stoddart, Chem. Soc. Rev. 2007, 36, 1705-1723.

[21] a) Y. Yang, R. C. da Costa, D.-M. Smilgies, A. J. Campbell, M. J. Fuchter, Adv. Mater. 2013, 25, 2624-2628; b) Y. Yang, R. C. da Costa, M. J. Fuchter, A. J. Campbell, Nat. Photon. 2013, 7, 634-638.

[22] a) K. Michaeli, N. Kantor-Uriel, R. Naaman, D. H. Waldeck, Chem. Soc. Rev. 2016, 45, 6478-6487; b) D. Zhao, T. van Leeuwen, J. Cheng, B. L. Feringa, Nat. Chem. 2016, 9, 250-256.

[23] A. Joosten, Y. Trolez, J.-P. Collin, V. Heitz, J.-P. Sauvage, J. Am. Chem. Soc. 2012, 134, 1802-1809.

[24] L. Brunsveld, B. J. B. Folmer, E. W. Meijer, R. P. Sijbesma, Chem. Rev. 2001, 101, 4071-4097.

[25] G. Xue, J. S. Bradshaw, N. K. Dalley, P. B. Savage, K. E. Krakowiak, R. M. Izatt, L. Prodi, M. Montalti, N. Zaccheroni, Tetrahedron 2001, 57, 7623 7628. 
[26] T. Qi, T. Deschrijver, I. Huc, Nat. Protoc. 2013, 8, 693-708.

[27] J. Lebowitz, M. S. Lewis, P. Schuck, Protein Sci. 2002, 11, 2067-2079.

[28] J. Roncali, Chem. Rev. 1997, 97, 173-206.
[29] CCDC 1519037 contains the supplementary crystallographic information for this paper. These data can be obtained free of charge from The Cambridge Crystallographic Data Centre. 


\section{Entry for the Table of Contents}

\section{COMMUNICATION}

Assembling polymers, with a twist:

The self-assembly of bifunctional subcomponents around $\mathrm{Cu}^{\prime}$ to yield a long, double helical metallopolymer is reported. Terminating groups are employed that govern the regiochemistry of the two strands within the polymer. Varying the stoichiometry of monomer to terminating group mediates the polymer length, giving rise to a tuneable hue of white light emission.

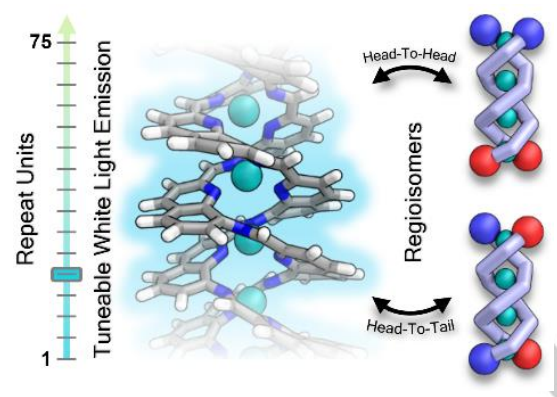

Jake L. Greenfield, Felix J. Rizzuto, leva Goldberga and Jonathan R. Nitschke*

Page No. - Page No.

Self-Assembly of Conjugated Metallopolymers with Tuneable Length and Controlled Regiochemistry 